\title{
Spatial Data modelling to study and improve waste management after hurricanes. The case of French West Indies
}

\author{
Ruas A. ${ }^{\mathrm{a}}{ }^{*}$, Lhomme S. ${ }^{\mathrm{b}}$ \\ ${ }^{a}$ LISIS/IFSTTAR/UPEM anne.ruas@ifsttar.fr \\ ${ }^{b}$ LAB'URBA/UPEC serge.lhomme@u-pec.fr \\ * Corresponding author
}

Keywords: Hurricane, waste management, waste transport modelling, data modelling, French west indies

\begin{abstract}
:
In the past decades, catastrophic natural disasters such as storms and hurricanes have impacted millions of people around the world: around 33 million of people are affected per year between 2007 and 2016 (Bellow and Wallemacq, 2018). For instance, hurricane Katrina (USA, 2015) caused catastrophic damage from central Florida to Eastern Texas, at least 1836 people died and total property damage was estimated at 125 billion dollars. Furthermore, climate change is likely to increase frequency of most intense categories of hurricanes in some parts of the world and is expected to increase sea levels, leading to more destructive storm surges when hurricanes occur (IPCC, 2013). In the same time, growing populations and rising incomes are expected to place more people and property in harm's way.
\end{abstract}

Depending on their nature and severity, disasters can create large volumes of debris and waste (Brown et al., 2011). In some cases, debris volume from a single event were the equivalent of 5-15 times the annual waste generation rates of the affected community (Reinhart and McCreanor, 1999). Often, the debris removal process takes months or even years to treated (Pramudita et al., 2014). In France, storm Xynthia (2010) waste generation was equivalent to about 12 normal years (CEPRI, 2012). Thus, waste can overwhelm existing solid management facilities and the presence of disaster waste impacts almost every aspect of an emergency response and recovery effort (Brown et al., 2011). For instance, in the immediate response, disaster debris can cause road blockages. Moreover, if poorly managed, the waste can have significant environmental and public health impacts (Brown et al., 2011), such as water and air pollution.

In this paper we present the Depos data modelling (named Depos-model) to improve the management of debris and waste after hurricanes. In the Depos project, funded by the French research agency (ANR), we intend to understand the process of waste management thanks to testimonies on previous hurricanes and to propose a digital modelling of waste management. In the following we do not distinguish debris and waste. The case study is the French west Indies (composed of different territories including the Guadeloupe and Martinique) and the very first island to study is the Island of Saint Martin in the Caribbean Sea where Irma hurricane (2017) had huge impact. This hurricane was the most powerful ever recorded hurricane in Atlantic with sustainable winds of nearly $300 \mathrm{~km} / \mathrm{h}$, with a gust to $360 \mathrm{~km} / \mathrm{h}$. The research work began with a study from the association Robin des Bois to describe and estimate waste after Irma on Saint Martin. These experts were questioned to identify the key entities and actors involved in hurricane waste management. We set a first data modelling that will be questioned and improved during the next 2 years. The deposmodel should be able 1- to replay what occurred during a previous hurricane, 2- to simulate different situations on fictive hurricanes and hopefully 3 - to be used after a future hurricane to improve waste management. In this paper we do not include the actors although they are key elements in the modelling. To introduce the data model, we decomposed it in different part. We first present the waste (figure 1) before presenting the transportation of waste to waste treatment areas (figure 3).

The first set of classes is the description of the waste generated either by previous hurricanes or by simulated ones (figure 1). In order to distinguish between historical data and simulated one, two classes are set for historical data (hurricane event and damage areas) and two classes are set for simulated data (hazard area and simulated-damage-area). One of the aims of the project is indeed to check if we are able to estimate waste type and volume for different hurricane scenario. Damage areas and simulated damage areas have geometries and each area is connected to waste data. Each waste data is defined by a type, a volume and a date. The differentiation of waste type is important because the transport and treatment of waste depends on its nature. We first distinguish domestic, organic (such as trees); mineral (such as concrete), metal and mixed waste. In our model waste is typically a temporal data as the volume changes over time. Of course, the waste type and volume depend on the strength of the hurricane and on the type of habitat. One of the challenges of the project is also to be able to estimate the waste type and volume from previous events and from available data on habitat computed thanks to topographic data and local knowledge. Thus, the function Estimate-waste in Figure 1 should include data on hurricane and on building material. Topographic data from BDtopo will thus be used to facilitate this estimation. Another important point is the temporal aspect of our Depos-model. If Hurricane lasts some hours, the damage areas are damaged for a much longer time. Waste is temporarily moved to collection points, often by inhabitants or other actors, before being transferred to other places (figure 2). Collection points are either designed by the authorities or spontaneously chosen by the inhabitants due to their availability and 
their location. Waste volume on collection point changes over time (red curve on figure 2). Practically, it is impossible to have frequent and regular information on data volume on collection point.

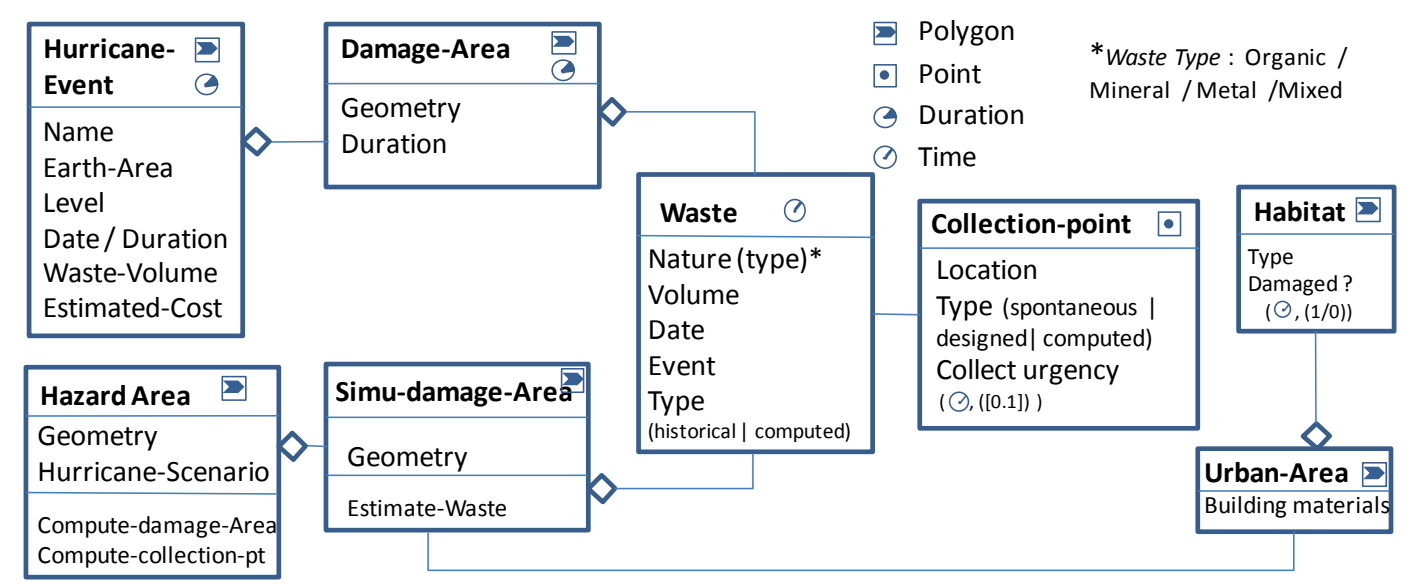

Figure 1. Data modelling: from damaged area to waste on collection point.
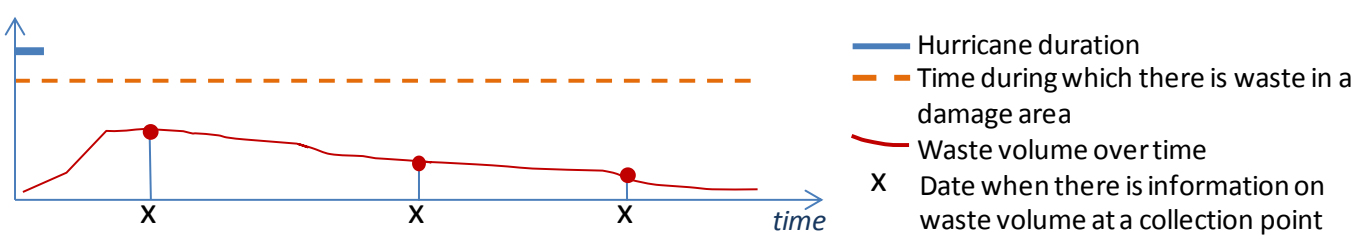

Figure 2. Duration of hurricane, duration of damage areas and evolution of waste volume over time

The second part of Depos-model (figure 3) is the transport of waste from collection points to waste areas such as the waste treatment factories, Dump, the waste warehouse -as dock warehouse before being transported to other islands or countries- or even illegal landfills or sea outfall. Collection points and these new destination points constitute the nodes of the transport network. Testimonies allow to store the waste trajectories build on existing transport network. In such a way, it is possible to reconstitute the waste flow after hurricane, to identify weaknesses for post disaster management and to propose scenario to improve the situation for next events.

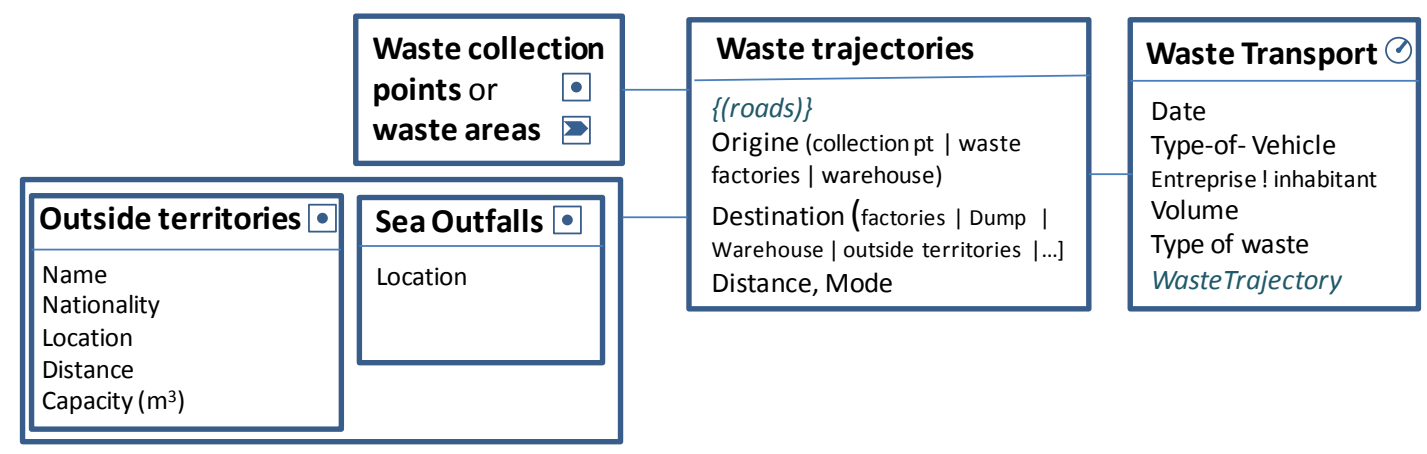

Figure 3. Data modelling: Transportation of waste through existing road network

\section{References}

Below, R., Wallemacq, P. (2018). Annual Disaster Statistical Review 2017, CRED, Centre for Research on the Epidemiology of Disasters.

Brown, C., Milke, M., Seville, E. (2011). Disaster waste management: A review article, Waste Management, 31(6), pp. 1085-1098.

CEPRI, 2012, Les collectivités territoriales face aux déchets des inondations : des pistes de solutions, Guide de sensibilisation.

Intergovernmental Panel on Climate Change, 2013. Climate Change 2013: The Physical Science Basis.

Pramudita A., Taniguchi E., Qureshi A. G., 2014, Location and Routing Problems of Debris Collection Operation after Disasters with Realistic Case Study, Procedia - Social and Behavioral Sciences, 125, pp. 445-458.

Reinhart D., Mc Creanor P., 1999, Disaster Debris Management - Planning Tools, Final Report, US Environmental Protection Agency Region IV 